\title{
Outcome of Teenage Pregnancy in Rural India with Particular Reference to Obstetrical Risk Factors and Perinatal Outcome
}

\author{
Indranil Dutta, Dilip Kumar Dutta, Prashant Joshi
}

\begin{abstract}
Objectives: The aim of the present study is to evaluate the outcome and complications in teenage primigravida when compared to primigravidae of adult age group.
\end{abstract}

\begin{abstract}
Materials and methods: A massive study involving 984 patients was undertaken. It was a prospective case control study was done for 30 months from July 2010 to January 2013 at Rural Medical College-Hospital, Karnataka. During this period booked and unbooked cases were included in the study and for every teenage primigravidae one subsequent adult primigravidae were studied. Patients with major skeletal deformity, such as kyphoscoliosis, polio, pelvic fracture, diabetes mellitus, renal disorders, morbid obesity, All cases of molar pregnancy and primigravidas admitted for abortion were excluded.
\end{abstract}

Results: Among 492 teenage and equal adult primigravidae, $51.8 \%$ of teenage were unbooked compared to $13.6 \%$ of adults. $68.4 \%$ of teenage were anemic compared to $33.32 \%$ of adults, antenatal complications like anemia, Hypertensive disorders of pregnancy, oligohydramnios, hypothyroid were significantly more in teenagers (69.5\%) compared to adults (19.3\%), 33.7\% of teenagers had preterm birth compared to $8.72 \%$ in adults. $48.3 \%$ of teenagers had LSCS compared to $21.9 \%$ of adults. Indication was CPD in majority of teenagers (45.4\%). $31.74 \%$ of teenagers had low birth weight child compared to $16.6 \%$ in adults and $34.5 \%$ of teenage neonates required NICU admission compared to $12.4 \%$ in adults.

Interpretation and conclusion: It can be interpreted that teenagers had significant number of complications in pregnancy including leading cause being anemia, more preterm incidences and higher rate of LSCS followed by higher number of NICU admission. Pregnancy itself has a tremendous effect on teenage and her family. Teenage pregnancy is more common in low socioeconomic status, due to lack of education, awareness of complications of teenage pregnancy, and various other factors. Hence awareness and various programmes should be taken up to educate mainly the poor in our rural setup. As early marriage cannot be prevented in our culture so possibly the awareness regarding late conception can be taken up as of utmost importance.

Keywords: Teenage pregnancy, Primigravidae, Anemia.

How to cite this article: Dutta I, Dutta DK, Joshi P. Outcome of Teenage Pregnancy in Rural India with Particular Reference to Obstetrical Risk Factors and Perinatal Outcome. J South Asian Feder Obst Gynae 2013;5(3):102-106.

Source of support: Nil

Conflict of interest: None declared

\section{INTRODUCTION}

Teenage pregnancy is a big problem in present day world mainly in the developing countries like India where still marriages take place early during the girls adolescent age and thus also resulting in early pregnancy. Various societal and personal factors are involved. The pregnancy rates vary between countries because of differences in levels of sexual activity, general sex education provided and access to affordable contraceptive options.

In England and Wales for example, in 1956, among girls aged 15 years, the chances of pregnancy was 0.8 per 1000 girls; but in 1973, the rate had increased to 4 per 1000 . At present the incidence in England and Wales is in between 2 and 44 per $1000 .{ }^{1}$ Spitz et $\mathrm{al}^{2}$ had noted that teenage pregnancy rate is considerably higher in USA with the incidence varying from 25 to 75 per 1000 for 15 to 17 years and 92 to 165 per 1000 for 18 to 19 years. In 1998 birth rate in 15 to 19 years old was 51.1 live births for 1000 population in USA. ${ }^{3}$ Data of the National Family Health Survey (NFHS)-3 revealed that $16 \%$ of women, aged 15 to 19 years, have already started childbearing. Early marriage sometimes means adolescent pregnancy, particularly in rural regions where the rate is much higher that is $21.21 \%{ }^{4}$ than it is in urbanized areas.

In India various studies done in past have shown that teenage pregnancy is a wide problem in our society and country. Studies in Bombay showed a rate of 33.17\%, ${ }^{5}$ Kolkata 15.7\%, Madurai 13.1\%, ${ }^{7}$ Hyderabad 5.1\%, ${ }^{8}$ and Coimbatore $12.69 \% .{ }^{9}$ Banerjee et $\mathrm{al}^{6}$ in a study in rural hospital, West Bengal had mentioned teenage mothers between 15 and 19 years old were more likely to have anemia, preterm delivery, and low birth weight than mothers between 20 and 24 years old. Chahande et $\mathrm{al}^{10}$ have reported early registration of pregnancy ranging from 40 to $90 \%$ in teenagers; however, the frequency of antenatal check-ups by them was consistently lower.

\section{Risk Factors for Teenage Pregnancy}

Risk factors mainly are linked to poverty, age at marriage, poor transition from school to work at 16 years of age, lower socioeconomic group, sexual abuse, low educational achievement, mental health problems, having had teenage parents, crime, out of wedlock pregnancy, social deprivation, being in the care of social services, other risks.

Complications of 11 studies in developing countries, eight found no difference, two found an increased risk for adolescents and one (Adedoyin et al) ${ }^{11}$ found less hypertension and more pre-eclampsia in adolescent. In India Aznar et $\mathrm{al}^{12}$ had observed 
an incidence of $10 \%$ eclampsia in their adolescent group and the frequency was more in girls less than 15 years (ACOG, 1998; National Health Statistics, 1997). An increased prevalence of anemia in young pregnant women was found in four of seven studies from developing countries included in review by Scholl et $\mathrm{al}^{13}$ and in two the difference was statistically significant. Wiesenfeld et $\mathrm{al}^{14}$ conducted a recent study in the USA revealed that one in five teenagers have an undiagnosed STI. In the USA, Leland et $\mathrm{al}^{15}$ compared the risk of preterm birth in pregnant adolescents and adults pregnancy outcomes among 38, 551 adolescents aged 10 to 14 years. In India, Aznar et al ${ }^{12}$ reported an increase in primary cesarean section rate by $28 \%$ in patients of 15 years or under. The characteristics of adolescent deliveries in developed countries are: lower percentage of episiotomies (Lubarsky et al 1994). ${ }^{16}$ Higher number of vaginal operative deliveries (Konje et al 1992), ${ }^{17}$ lower (Jolly et al 2000) or equal (Lubarsky et al, 1994), lower incidence of inductions (Jolly et al 2000), a lower incidence of oxytocin use (Lubarsky et al 1994), ${ }^{16}$ shorter duration of active phase of labor in adolescents. In developed countries, the incidence of LBW or VLBW in infants of adolescent mothers was higher compared to infants of older mothers (Miller et al, 1996). ${ }^{18}$

\section{MATERIALS AND METHODS}

This was a prospective case control study of 492 teenage mothers compared with 492 mothers in adult age group, done in Department of Obstetrics and Gynecology in Rural Medical College-Hospital from July 2010 to January 2013. Written informed consent was taken. The socioeconomic status,

\begin{tabular}{lccccc}
\multicolumn{5}{c}{ Table 1: Education } \\
\hline Education & \multicolumn{2}{c}{ Teenage } & \multicolumn{2}{c}{ Adult } \\
\hline No. education/schooling at all & 264 & $53.6 \%$ & 44 & $8.9 \%$ \\
\hline
\end{tabular}

\begin{tabular}{|c|c|c|c|c|}
\hline \multirow[t]{3}{*}{ Antenatal care } & \multirow{2}{*}{\multicolumn{2}{|c|}{$\frac{\text { Teenage primigravida }}{(n=492)}$}} & \multirow{2}{*}{\multicolumn{2}{|c|}{$\frac{\text { Adult primigravida }}{(n=492)}$}} \\
\hline & & & & \\
\hline & No. & $\%$ & No. & $\%$ \\
\hline Booked & 237 & 48.2 & 425 & 85.4 \\
\hline Unbooked & 255 & 51.8 & 67 & 13.6 \\
\hline Total & 492 & 100.0 & 492 & 100.0 \\
\hline
\end{tabular}

\begin{tabular}{|c|c|c|c|c|}
\hline \multirow{3}{*}{$\begin{array}{l}\text { Anemia } \\
(\mathrm{Hb})\end{array}$} & \multirow{2}{*}{\multicolumn{2}{|c|}{$\frac{\text { Teenage primigravida }}{(n=492)}$}} & \multirow{2}{*}{\multicolumn{2}{|c|}{$\frac{\text { Adult primigravida }}{(n=492)}$}} \\
\hline & & & & \\
\hline & No. & $\%$ & No. & $\%$ \\
\hline$\geq 11$ & 155 & 31.6 & 328 & 66.67 \\
\hline $10.0-10.9$ & 129 & 26.2 & 125 & 25.4 \\
\hline $7.0-9.9$ & 184 & 37.4 & 33 & 6.7 \\
\hline $4.1-6.9$ & 24 & 4.8 & 6 & 1.22 \\
\hline$\leq 4.0$ & 0 & 0 & 0 & 0 \\
\hline Total & 492 & 492 & 492 & 492 \\
\hline
\end{tabular}

education, religion, onset of menarche, marital status, number of antenatal visits was be recorded. A thorough general and obstetrics examination was done. Investigation such as hemoglobin estimation, urine analysis, VDRL test, HIV, HBsAg, Blood grouping and Rh typing was done. Any medical or obstetrical problem in antenatal, intranatal or postnatal period was noted. Labor and its progress was closely monitored. Mode of delivery and perinatal outcome was noted on both groups. The statistical significance was considered at $p$-value $<0.05$. Inclusion criteria all booked and unbooked primigravida cases attending Rural Medical College Hospital, Karnataka. For every teenage primigravida pregnancy one subsequent adult primigravida was studied. Exclusion criteria mothers having major skeletal deformity such as kyphoscoliosis, polio, pelvic fracture, diabetes mellitus, known hypertensive, renal disorders, morbid obesity. All cases of molar pregnancy and primigravidas admitted for abortion were excluded.

\section{RESULTS}

Education: It was seen that $53.6 \%$ teenage had not attended school compared to $8.9 \%$ in adults (Table 1 ).

Booking: Unbooked cases were significantly more in teenage primigravida group with $\mathrm{p}<0.001$ compared to adults (Table 2).

Complications: Mean hemoglobin levels is significantly less associated with teenage primigravida group with $\mathrm{p}<0.001$ (Table 3). Anemia was the most common complication (68.4\%) in teenage compared to $(33.32 \%)$ adults.

Incidence of antenatal complications are significantly more associated with teenage primigravida group (69.5\%) when

\begin{tabular}{lccccc}
\multicolumn{4}{c}{ Table 4: Antenatal complications } \\
\cline { 1 - 2 } $\begin{array}{l}\text { Antenatal } \\
\text { complications }\end{array}$ & $\begin{array}{c}\text { Teenage primigravida } \\
(n=492)\end{array}$ & \multicolumn{2}{c}{$\begin{array}{c}\text { Adult primigravida } \\
(n=492)\end{array}$} \\
\cline { 2 - 3 } \cline { 6 - 6 } & No. & $\%$ & & No. & $\%$ \\
\hline Absent & 150 & 30.5 & & 397 & 80.7 \\
Present & 342 & 69.5 & & 95 & 19.3 \\
Hypertensive disorder & 91 & 18.5 & & 35 & 7.1 \\
of pregnancy & & & & & \\
Anemia & 337 & 68.4 & & 164 & 33.75 \\
ECC & 7 & 1.4 & & 4 & 0.8 \\
Oligohydramnios & 12 & 2.4 & & 6 & 1.2 \\
Hypothyroid and IE & 0 & 0.0 & & 7 & 1.4 \\
IUGR & 7 & 1.4 & & 3 & 0.6 \\
Preterm & 166 & 33.7 & & 25 & 5 \\
RHD & 1 & 0.2 & & 0 & 0.0 \\
IUD & 1 & 0.2 & & 0 & 0.0 \\
Twins & 2 & 0.4 & 3 & 0.6 \\
\hline
\end{tabular}

\begin{tabular}{lccccc}
\multicolumn{3}{c}{ Table 5: Gestational age } \\
\cline { 1 - 2 } $\begin{array}{l}\text { Gestational } \\
\text { age }\end{array}$ & $\begin{array}{c}\text { Teenage primigravida } \\
(n=492)\end{array}$ & & $\begin{array}{c}\text { Adult primigravida } \\
(n=492)\end{array}$ \\
\cline { 2 - 3 } \cline { 5 - 6 } & No. & $\%$ & & No. & $\%$ \\
\hline $28-32$ & 0 & 0.0 & & 4 & 0.8 \\
32 & 12 & 2.5 & & 7 & 1.42 \\
34 & 77 & 15.6 & & 32 & 6.5 \\
$34-36$ & 77 & 15.6 & & 0 & 0.0 \\
Term & 326 & 66.3 & & 449 & 91.3 \\
\hline
\end{tabular}


compared to adult primigravida $(19.3 \%)$ with $\mathrm{p}<0.001$. Anemia was the most common complication (68.4\%) in teenage compared to (33.32\%) adults followed by PIH (Table 4).

Gestational age suggests that more preterm are significantly associated with teenage primigravida with $\mathrm{p}<0.001$ (Table 5).

LSCS is significantly more with teenage primigravida $(43.8 \%)$ compared to adults $(21.9 \%)$ with $\mathrm{p}<0.001$ (Table 6).

Incidence of CPD and fetal distress are significantly more associated with teenage primigravida with $\mathrm{p}=0.003$ (Table 7).

Perinatal meconium stained liquor was seen in $15 \%$ of the cases of teenage primi compared to $5 \%$ in adults, and 4 cases of PPH in teenage compared to 3 in adults. Around $15 \%$ of teenage group required blood transfusion compared to $5.6 \%$ of adults. Whole blood was transfused due to lack of component availability in our institute.

A total of $15.8 \%$ of neonate had an Apgar score of 1 minutes less than 7 and 5 minutes score less than 9 in the teenage group whereas $16.6 \%$ of neonate had apgar score in 1 minute less than 7 and 5 minutes score less than 9 of adults (Table 8).

Incidence of low birth weight is significantly more in teenage group (31.74\%) compared to adults (16.6\%) with $\mathrm{p}=0.019$ (Table 9).

A total of $29.2 \%$ of neonates belonging to teenage mother were having birth asphyxia hence requiring neonatal

\begin{tabular}{lccccc}
\multicolumn{5}{c}{ Table 6: Mode of delivery } \\
\hline $\begin{array}{l}\text { Mode of } \\
\text { delivery }\end{array}$ & \multicolumn{2}{c}{$\begin{array}{c}\text { Teenage primigravida } \\
(n=492)\end{array}$} & & $\begin{array}{c}\text { Adult primigravida } \\
(n=492)\end{array}$ \\
\cline { 2 - 3 } \cline { 6 - 6 } & No. & $\%$ & & No. & $\%$ \\
\hline Normal vaginal & 227 & 46.2 & & 362 & 73.56 \\
Instrumental (OF + V) & 27 & 5.4 & & 22 & 4.6 \\
LSCS & 238 & 48.3 & & 108 & 21.9 \\
\hline Total & 492 & 100.0 & & 492 & 100.0 \\
\hline
\end{tabular}

\begin{tabular}{lccccc}
\multicolumn{3}{c}{ Table 7: Indication for LSCS } \\
\hline Indication & $\begin{array}{c}\text { Teenage primigravida } \\
(n=238)\end{array}$ & & $\begin{array}{c}\text { Adult primigravida } \\
(n=108)\end{array}$ \\
\cline { 2 - 3 } \cline { 6 - 7 } & No. & $\%$ & & No. & $\%$ \\
\hline CPD & 108 & 45.4 & & 32 & 29.6 \\
Fetal distress (FD) & 70 & 29.4 & & 40 & 37.03 \\
Failed induction (FI) & 52 & 21.8 & & 16 & 14.8 \\
Breech & 8 & 3.3 & & 20 & 18.5 \\
\hline
\end{tabular}

\begin{tabular}{|c|c|c|c|c|}
\hline \multicolumn{5}{|c|}{ Table 8: Apgar score at birth } \\
\hline \multirow[t]{2}{*}{ Baby apgar } & \multicolumn{2}{|c|}{$\begin{array}{l}\text { Teenage primigravida } \\
\qquad(n=493)\end{array}$} & \multicolumn{2}{|c|}{$\begin{array}{l}\text { Adult primigravida } \\
\qquad(n=495)\end{array}$} \\
\hline & No. & $\%$ & No. & $\%$ \\
\hline \multicolumn{5}{|c|}{ Apgar 1 minute } \\
\hline$<7$ & 78 & 15.8 & 82 & 16.6 \\
\hline$>7$ & 415 & 84.2 & 410 & 83.4 \\
\hline \multicolumn{5}{|c|}{ Apgar 5 minutes } \\
\hline$<9$ & 78 & 15.8 & 82 & 16.6 \\
\hline$>9$ & 415 & 84.2 & 410 & 83.4 \\
\hline
\end{tabular}

resuscitation compared to $7.3 \%$ in adult group. Whereas $11.9 \%$ of neonates belonging to teenage mother had neonatal hyperbilirubinemia compared to $4.8 \%$ in adults (Table 10 ).

\section{DISCUSSION}

Teenage pregnancy is a problem in developing countries like India. The main aim of the study was to observe the maternal and perinatal outcome in teenage mothers compared to similar number of mothers in adult group.

Present study highlights, majority of patients were of low socioeconomic status in both study and control group. This is mostly due to poor educational status in the teenage mothers. Most of teenage mothers $(53.6 \%)$ have not had primary education itself compared to $8.9 \%$ in adults. $51.8 \%$ of teenage mothers were unbooked compared to $13.6 \%$ in adults. "Tetanus immunization was given to most of the patients. It was noted that Anemia was one of the main complications in the study". Study by Verma $\mathrm{V}^{19}$ and Shravage $\mathrm{JC}^{20}$ also showed high rates of teenage mothers with anemia compared to adult mothers as depicted in our study probably because of poor nutrition in this group of women. To counter this problem more focused national programs like FOGSI 12 by 12 where aim is $12 \mathrm{gm}$ of $\mathrm{Hb} \%$ by the age of 12 are necessary (Table 11 ).

Teenage pregnancy is a known risk factor for developing pre-eclampsia and in the present study, the chances of developing pre-eclampsia was 3 times more common in teenage mothers than adult mothers. The findings are comparable with

\begin{tabular}{lccccc}
\multicolumn{3}{c}{ Table 9: Baby birth weight } \\
\cline { 1 - 2 } $\begin{array}{l}\text { Baby birth } \\
\text { weight }\end{array}$ & \multicolumn{2}{c}{$\begin{array}{c}\text { Teenage } \\
(n=494)\end{array}$} & & \multicolumn{2}{c}{$\begin{array}{c}\text { Adult } \\
(n=495)\end{array}$} \\
\cline { 2 - 3 } \cline { 6 - 7 } & No. & $\%$ & & No. & $\%$ \\
\hline 4499 gm & 7 & 1.42 & & 0.9 \\
$1500-1999 \mathrm{gm}$ & 7 & 1.42 & & 1.8 \\
$2000-2499 \mathrm{gm}$ & 143 & 28.9 & & 69 & 13.9 \\
$2500-2999 \mathrm{gm}$ & 192 & 38.7 & & 163 & 32.9 \\
$3000-3499 \mathrm{gm}$ & 138 & 27.8 & & 150 & 30.3 \\
$3500-3999 \mathrm{gm}$ & 5 & 2.02 & & 54 & 10.9 \\
$\geq 4000 \mathrm{gm}$ & 0 & 0 & & 46 & 9.2 \\
\hline Total & 80 & 100.0 & 160 & 100.0 \\
\hline
\end{tabular}

\begin{tabular}{|c|c|c|c|c|}
\hline \multicolumn{5}{|c|}{ Table 10: Neonatal morbidity and mortality } \\
\hline \multirow[t]{2}{*}{$\begin{array}{l}\text { Neonatal } \\
\text { morbidity/mortality }\end{array}$} & \multicolumn{2}{|c|}{$\begin{array}{l}\text { Teenage } \\
(n=494)\end{array}$} & \multicolumn{2}{|c|}{$\begin{array}{c}\text { Adult } \\
(n=495)\end{array}$} \\
\hline & No. & $\%$ & No. & $\%$ \\
\hline Birth asphyxia & 144 & 29.2 & 36 & 7.3 \\
\hline Neonatal resuscitation & 144 & 29.2 & 36 & 7.3 \\
\hline NICU care & 157 & 31.74 & 82 & 16.6 \\
\hline $\begin{array}{l}\text { Neonatal } \\
\text { hyperbilirubinemia }\end{array}$ & 59 & 11.9 & 24 & 4.8 \\
\hline RDS & 36 & 7.3 & 12 & 2.45 \\
\hline $\begin{array}{l}\text { Meconium stained } \\
\text { amniotic fluid }\end{array}$ & 72 & 14.6 & 33 & 6.7 \\
\hline $\begin{array}{l}\text { Meconium aspiration } \\
\text { syndrome }\end{array}$ & 48 & 9.7 & 18 & 3.68 \\
\hline Sepsis & 12 & 2.4 & 3 & 0.61 \\
\hline Congenital anomaly & 0 & 0 & 0 & 0 \\
\hline
\end{tabular}


that of Verma V, Shravage JC and Bhaduria studies, which also showed higher rates of pre-eclampsia in teenage mothers, when compared to adult primigravidas (Table 12).

In the present study $7.1 \%$ of teenage mothers had preeclampsia, eclampsia syndrome. Shravage JC also noted high incidence of eclampsia in teenage primigravidas.

In the present study, preterm delivery is 4 times more common in teenage primigravidas compared to adult primigravidas. Bhaduria, Bhattacharya and Shravage JC studies showed high incidence of preterm delivery in teenage primigravidas. This could be explained due to high incidence of pre-eclampsia and anemia in the teenager group (Table 13).

In the present study, $25 \%$ of teenage study mothers and $23.2 \%$ of adult mother delivered within 6 hours. $67.5 \%$ of teenage mothers and $66.8 \%$ of adult mothers delivered within 12 hours. With active management of labor, there is no difference of duration of labor in both the groups. No mother delivered after 24 hours in both study and control groups. In comparison there was not much difference between study and control group. In the present study, there was lower number of normal vaginal deliveries $(46.2 \%)$ in teenage primigravidas when compared to adult primigravidas $(73.56 \%)$. This is consistent with other studies such as verma study ${ }^{19}$ and shravage study $^{20} 21.5 \%$ and the probable reason for this is due to immaturity and underdeveloped bony pelvis in teenagers.

Incidence of LSCS in teenage primigravidas were higher (48.3\%) when compared to adult primigravidas (21.9\%), i.e. almost double the incidence that of in adults comparable to Shravage study ${ }^{20}$ and Chhabra study. ${ }^{22}$ Most common indication for LSCS was CPD in teenage group mostly due to immature pelvis. In other studies like Shravage study ${ }^{20}$ also, the most common indication was cephalopelvic disproportion followed by fetal distress.

Operative interventions were $5.4 \%$ in teenage primigravida and $4.6 \%$ in adult primigravida. Higher incidence of operative

\begin{tabular}{|c|c|c|}
\hline & Teenage & Adult \\
\hline Present study (<11 gm) & $68.4 \%$ & $33.32 \%$ \\
\hline Verma V study ${ }^{19}$ & $35 \%$ & $25 \%$ \\
\hline Nayak et $\mathrm{al}^{21}$ & $12.98 \%$ & - \\
\hline Chhabra et al ${ }^{22}$ & $70 \%$ & - \\
\hline Shravage JC study ${ }^{20}$ & $84.2 \%$ & $34.2 \%$ \\
\hline Pal Amitha et $a^{23}$ & $27.5 \%$ & $11.2 \%$ \\
\hline Ashok Kumar, $2007<11 \mathrm{gm}^{24}$ & $62.9 \%$ & - \\
\hline
\end{tabular}

Table 12: Comparison of pre-eclampsia with respect to other studies

\begin{tabular}{|c|c|c|}
\hline & Teenage & Adult \\
\hline Present study & $18.5 \%$ & $7.1 \%$ \\
\hline Verma V study ${ }^{19}$ & $18.8 \%$ & $11.5 \%$ \\
\hline Shravage JC study ${ }^{20}$ & $37 \%$ & $25 \%$ \\
\hline Russel study ${ }^{25}$ & $20.2 \%$ & - \\
\hline Pawar S study ${ }^{26}$ & $20 \%$ & - \\
\hline Bhaduria study ${ }^{27}$ & $23.7 \%$ & - \\
\hline Pal Amitha et $\mathrm{al}^{23}$ & $15 \%$ & $8.7 \%$ \\
\hline
\end{tabular}

deliveries in teenage group was also found in other studies like in Pal Amitha et $\mathrm{al}^{23}$ and Shravage et al. ${ }^{22}$ Complication like wound gaping (including CS and episiotomy) was 12.5\% in teenage compared to $3.7 \%$ in adults. Around $5 \%$ of teenage group required blood transfusion compared to $1.25 \%$ of adults.

Regarding perinatal morbidity and mortality the present study showed higher incidence of low birth weight babies born to teenage primigravidas. Shravage JC and Kushwaha studies also showed high incidence of low birth weight in teenage primigravidas. Babies born to teenagers are more likely than those born to women in their 20s to be born early and to weigh less than 2500 gm at birth. In our study LBW was in $31.74 \%$ compared to adult group which was $16.6 \%$ of the babies born. Some of the explanations proposed for these adverse outcomes are biological. Biological immaturity in teenage mothers itself is an inherent risk factor for poor outcome and even adequate prenatal care does not completely eliminate the risk. Two general features of biologic immaturity could have a role in increasing the risk of adverse outcomes: a young gynecologic age (defined as conception within two years after menarche) and the effect of the girl becoming pregnant before her own growth has ceased, thus competing with the developing fetus for nutrients adding to its detriment. The main cause of premature and LBW babies may be poor nutritional status, preeclampsia and anemia may be additional reason for premature and low birth weight babies. Among neonatal morbidities, incidence of birth asphyxia, RDS and neonatal hyperbilirubinemia were significantly more in the teenager group. Most probable reason would be higher number of premature and low birth weight babies in this age group. Most of the other studies present the same results. ${ }^{24}$

\section{CONCLUSION}

From the present study it is concluded that teenage mothers in rural population had significant number of complications in pregnancy such as anemia, pre-eclampsia and preterm labor as compared to primigravidae in their twenties. Maternal morbidity was more due to increased operative interference, higher rate of LSCS and higher number of NICU admissions. Pregnancy itself has a tremendous effect on teenage mother and her family. To prevent teenage pregnancy and its complications following five observations are to be advocated: (1) awareness not to marry before 20 year, (2) avoid pregnancy before 20 years if married mainly due to socioeconomic problems, by contraception (OC pills and condom), (3) alert to find out early complications and prompt treatment, (4) audit should be done if she dies during pregnancy and (5) assure her

\begin{tabular}{|c|c|c|}
\hline \multicolumn{3}{|c|}{$\begin{array}{l}\text { Table 13: Comparison of preterm delivery with } \\
\text { respect to other studies }\end{array}$} \\
\hline Preterm delivery & Teenage & Adult \\
\hline Present study & $33.7 \%$ & $8.72 \%$ \\
\hline Bhaduria et $\mathrm{al}^{27}$ & $30 \%$ & - \\
\hline Bhattacharya et $\mathrm{al}^{28}$ & $34.6 \%$ & - \\
\hline Shravage JC study ${ }^{20}$ & $28.5 \%$ & $24.2 \%$ \\
\hline Ashok Kumar, $2007^{24}$ & $26.1 \%$ & - \\
\hline
\end{tabular}


well being after delivery by providing proper nutrition, education, instating of family planning program to prevent further pregnancy (by postpartum IUCD).

\section{REFERENCES}

1. Teenage Pregnancy in Britain Birth Control Trust. London Bury. British Journal of Obstet Gynaecol 1985;92:1081-1083.

2. Spitz AM, Ventera SJ. Surveillance for pregnancy and birth rates among teenagers by state - United States. Adolescent Health 1993;42(6):1-27.

3. National Center for Health Statistics. Technical appendix. Vital statistics of the United States: Mortality 2000. Available on: NCHS Website at: www.cdc.gov/nchs/data/nvsr/nvsr48/ nvs48_11: 2000; 48(3):100pp (PHS) [Accessed Oct 2011]: 1120-00.

4. Goswami BK, Goswami BJ. Teenage pregnancy. Obstet Gynaec India 1989;39:475-478.

5. Pratinidhi A, Shrotri A, Shah U. Risk of teenage pregnancy in a rural community of India. Indian J Matern Child Health 1990 Oct-Dec;1(4):134-138.

6. Banerjee B, Pandey GK, Dutt D, Sengupta B, Mondal M. Teenage pregnancy: a socially inflicted health hazard. Indian J Community Med 2009;34:227-231.

7. Philips PS, Sundar SK. Teenage pregnancy. J Obstet Gynaec India 1978;28:576-581.

8. Pachauri S, Jamshedji A. Risk of teenage pregnancy. J Obstet and Gynecol India 1933;33:477-481.

9. Seeniammal. Problem of teenage pregnancy. Handbook 1983: 125-136.

10. Chahande MS, Jadho AR, Wadhva SK, Udhade S. Study of some epidemiological factors in teenage pregnancy hospital based case comparison study. Indian J Community Med 2002;27:106-109.

11. Adedoyin MA, Adetoro O. Pregnancy and its outcome among teenage mothers in Ilorin, Nigeria, East African Med J 1989;66:448-452.

12. Aznar R, Bennet AE. Pregnancy in the adolescent girl. Am Obstet Gynaec 1961;81:934.

13. Scholl TO, Hediger ML, Belsky DH. Prenatal care and maternal health during adolescent pregnancy: a review meta-analysis. J Adolescent Health 1994;15:444-456.

14. Wiesenfeld HC, Lowry DL, Heine RP, Krohn MA, Bittner H, Kellinger K, et al. Self-collection of vaginal swabs for the detection of Chlamydia, gonorrhea, and trichomoniasis: opportunity to encourage sexually transmitted disease testing among adolescents. Sex Transm Dis 2001;28:321-325.
15. Leland NL, Petersen DJ, Braddock M, Alexander GR. Variations in pregnancy outcomes by race among 10-14 years old mothers in United States. Public Health Report 1995;110:53-58.

16. Lubarsky SL, Schiff E, Friedman SA, Mercer BM, Sibai BM. Obstetric characteristics among nulliparas under age 15. Obstet Gynaecol 1994; 84:365-368.

17. Konje JC, Palmer A, Watson A. Early teenage pregnancies in Hull. Br J Obstet Gynaecol 1992;99:969-973.

18. Miller PM, Plant M. Drinking, smoking, and illicit drug use among 15 and 16 year olds in the United Kingdom. BMJ 1996;313:394-397.

19. Verma V, Das KB. Teenage primigravida: a comparative study. Indian J Public Health 1997;41:52-55.

20. Shravage JC. Maternal and perinatal outcome in teenage pregnancy as compared to primigravida aged 20-29 years: a cross-sectional study. J Obs and Gynae 2000;7:32-43.

21. Nayak AH, Puraik KG, Dala AR. Obstetrics outcome in teenage pregnancy. J Obstet Gynec India 1992;42:442-446.

22. Chhabra S. Perinatal outcome in teenage mothers. J Obstet Gynec India 1991;41:30-32.

23. Pal A, Gupta KB, Randhawa I. Adolescent pregnancy: a high risk group. J Indian Med Assoc 1997;95:127-128.

24. Kumar A, Singh T, Basu S, Pandey S. Outcome of teenage pregnancy. Indian Journal of Pediatrics 2007;74(10):927-931.

25. Russel JK. Early teenage pregnancy. Am J Obstet and Gynecol 1982;3:1.

26. Pawar S. Teenage pregnancy. Indian Journal of Obs and Gynae 1987;89:119-121.

27. Bhaduria S, Singh S, Sankar B. Teenage pregnancy: a retrospective study. J Obstet Gynae India 1991;41:454-456.

28. Bhattacharya A, Chowdhury N. Teenage primigravida. Journal of Obstet Gynec India 1986;36:660.

\section{ABOUT THE AUTHORS}

\section{Indranil Dutta (Corresponding Author)}

Assistant Professor, Department of Obstetrics and Gynecology, IQ City Medical College, Durgapur, West Bengal, India, Phone: 91-9051556424, e-mail: drindranildutta@gmail.com

\section{Dilip Kumar Dutta}

Senior Consultant, Department of Obstetrics and Gynecology, GICE Hospital, Nadia, West Bengal, India

\section{Prashant Joshi}

Associate Professor, Department of Obstetrics and Gynecology Adichunchanagiri Institute of Medical Sciences, Bellur, Karnataka India 